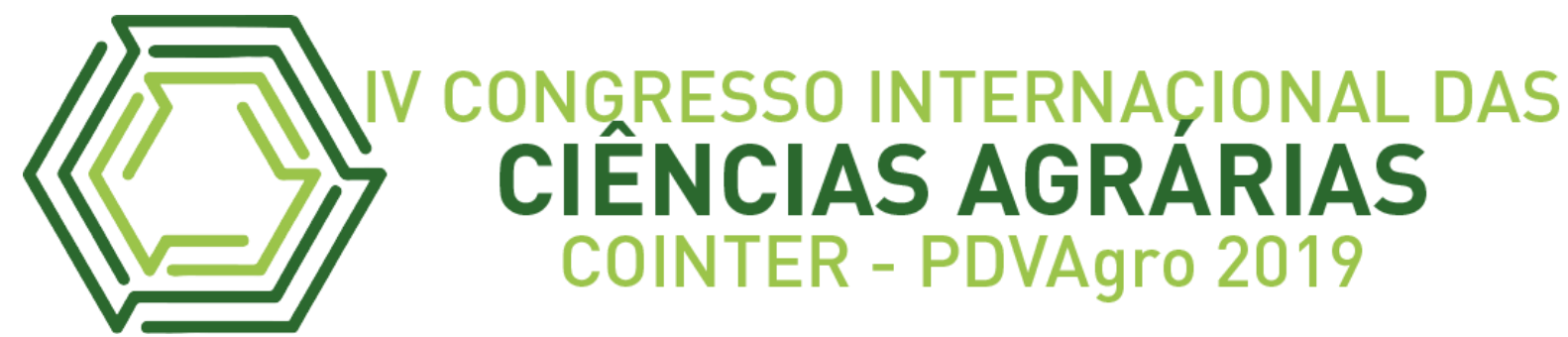

\title{
TEORES DE MACRONUTRIENTES E SÓDIO EM PLANTAS DE COUVE-FLOR UTILIZANDO ÁGUAS SALOBRAS EM CULTIVO HIDROPÔNICO
}

\section{CONTENIDO DE MACRONUTRIENTES Y SODIO EN PLANTAS DE COLIFLOR COM AGUA SALOBRE EN CULTURA HIDROPÓNICA}

\section{MACRONUTRIENT AND SODIUM CONTENTS IN CAULIFLOWER PLANTS USING BRACKISH WATER IN HYDROPONIC CULTURE}

\author{
Apresentação: Comunicação Oral \\ Julyane Silva Mendes Polycarpo ${ }^{1}$; Marco Antonio Silva² ${ }^{2}$ Hammady Ramalho e Soares $^{3}$ \\ Pollyanna C. Dos S. De Souza ${ }^{4}$; Ênio Farias de França e Silva ${ }^{5}$
}

DOI: $\underline{\text { https://doi.org/10.31692/2526-7701.IVCOINTERPDVAgro.2019.0089 }}$

\begin{abstract}
Resumo
Realizar o diagnóstico do estado nutricional das plantas por meio da análise dos seus tecidos vegetais é importante para que sua nutrição mineral seja conduzida no momento mais adequado e em quantidades apropriadas. Em função do exposto,o experimento foi conduzido em ambiente protegido no Departamento de Engenharia Agrícola da Universidade Federal Rural de Pernambuco (UFRPE), onde objetivou-se avaliar os teores de macronutrientes e sódio em plantas de couve-flor (cv. Piracicaba Precoce), produzida em sistema hidropônico NFT (fluxo laminar de nutrientes) e submetidas a diferentes níveis de salinidade da água usada no preparo da solução nutritiva, avaliando, também, a condutividade elétrica (CE) e pH da solução. A estrutura possuiu os perfis hidropônicos em polipropileno, diâmetro comercial de $150 \mathrm{~mm}$, comprimento de 2,5 m, com espaçamentos de $0,50 \mathrm{~m}$ entre plantas por $0,90 \mathrm{~m}$ entre os perfis, totalizando cinco plantas por perfil. $\mathrm{O}$ delineamento experimental foi o inteiramente casualizado em um esquema fatorial (6x2) referente a seis níveis de salinidade da água $\left(0,2 ; 1,5 ; 2,5 ; 3,5 ; 4,5\right.$ e $\left.5,5 \mathrm{dS} \mathrm{m}^{-1}\right)$ e duas vazões de aplicação da solução nutritiva $(1,5$ e 2,5 $\mathrm{L} \mathrm{min}^{-1}$ ), com quatro repetições totalizando 48 parcelas experimentais, produzidas com a aplicação de $\mathrm{NaCl}$ na água de abastecimento, sendo estas águas utilizadas no preparo da solução nutritiva e na reposição do volume evapotranspirado. Em ambas as vazões se constatou tendência de aumento da condutividade elétrica da solução (CEsol) nos tratamentos de maiores níveis de salinidade da água utilizada $\left(4,5\right.$ e $\left.5,5 \mathrm{dS} \mathrm{m}^{-1}\right)$, porém, na vazão de $2,5 \mathrm{~L}$ $\min ^{-1} \mathrm{e}$, para os mesmos níveis $\left(4,5 \mathrm{e} 5,5 \mathrm{dS} \mathrm{m}^{-1}\right)$, verificou-se acréscimos mais acentuados. $\mathrm{O}$

\footnotetext{
${ }^{1}$ Graduanda em Gestão Ambiental, Instituto Federal de Pernambuco, julyanemendes@gmail.com

${ }^{2}$ Mestrando em Engenharia Agrícola, Universidade Federal Rural de Pernambuco, gillyart@hotmail.com

${ }^{3}$ Doutor em Engenharia Agrícola, Universidade Federal Rural de Pernambuco, hresoares@hotmail.com

4 Graduanda em Bacharelado em Ciências Biológicas, Universidade Federal Rural de Pernambuco, pollycavalcanti.ss@hotmail.com

${ }^{5}$ Prof ${ }^{\circ}$ Doutor em Irrigação e Drenagem, Universidade Federal Rural de Pernambuco, enio.fsilva@ufrpe.br
} 
$\mathrm{pH}$ da solução nutritiva permaneceu dentro da faixa de normalidade para ambas as vazões. $\mathrm{O}$ aumento da salinidade proporcionou aumento nos teores de sódio e cloreto, e redução nos teores de potássio, fósforo, cálcio, magnésio na folha diagnóstico. $\mathrm{O}$ teor de enxofre não foi influenciado significativamente.

Palavras-Chave: Brassica olerácea L., hidroponia, salinidade

\title{
Resumen
}

El diagnóstico del estado nutricional de las plantas mediante el análisis de sus tejidos vegetales es importante para que su nutrición mineral se realice en el momento más apropiado y en cantidades apropiadas. Dado lo anterior, el experimento se realizó en un ambiente protegido en el Departamento de Ingeniería Agrícola de la Universidad Federal Rural de Pernambuco (UFRPE), donde el objetivo era evaluar el contenido de macronutrientes y sodio en las plantas de coliflor (cv. Piracicaba Precoce), producido en un sistema hidropónico de NFT ( flujo laminar de nutrientes) y sometido a diferentes niveles de salinidad del agua utilizada en la preparación de la solución nutritiva, también evaluando la conductividad eléctrica (CE) e el pH de la solución. La estructura tenía perfiles hidropónicos de polipropileno, diámetro comercial de $150 \mathrm{~mm}$, longitud de $2.5 \mathrm{~m}$, con separaciones de $0.50 \mathrm{~m}$ entre plantas por $0.90 \mathrm{~m}$ entre perfiles, totalizando cinco plantas por perfil. El diseño experimental fue completamente al azar en un esquema factorial (6x2) referido a seis niveles de salinidad del agua $\left(0.2,1.5,2.5,3.5,4.5\right.$, y $\left.5.5 \mathrm{dS} \mathrm{m}^{-1}\right)$, con cuatro repeticiones que totalizan 48 parcelas experimentales, producidas por la aplicación de NaCL en el agua de suministro, estas aguas se utilizan en la preparación de la solución nutricional y reemplazo del volumen evapotranspirado. En ambos caudales se verificó una tendencia al aumento de la conductividad elétrica de la solución (CEsol) en los tratamientos de niveles de salinidad más altos del agua utilizada ( 4.5 y $5.5 \mathrm{dSm}^{-1}$ ), sin embargo, en el flujo de $2.5 \mathrm{~L}$ min-1y, para los mismos niveles ( 4.5 y $5.5 \mathrm{dS} \mathrm{m}^{-1}$ ), hubo incrementos más significativos. El pH de la solución nutritiva se mantuvo dentro del rango normal para ambos caudales. El aumento en la salinidad proporcionó un aumento en los contenidos de sodio y coruro, y una rección en los contenidos de potasio, fósforo, calcio y magnesio en la hoja de diagnóstico. El contenidode azufre no fue inflenciado significativamente.

Palabras Clave: Brassica olerácea L., Hidroponía, Salinidad

\begin{abstract}
O resumo traduzido em inglês, Times New Roman 12, espaçamento simples. Diagnosing the nutritional status of plants by analyzing their plant tissues is important for their mineral nutrition to be conducted at the most appropriate time and in appropriate quantities. Due to the above, the experiment was conducted in a protected environment at the Department of Agricultural Engineering of the Federal Rural University of Pernambuco (UFRPE), where the objective was to evaluate the macronutrients and sodium contents in cauliflower (cv. Piracicaba Precoce) plants, produced in hydroponic NFT system ( laminar flow of nutrients) and submitted to different levels of salinity of the water used in the preparation of the nutrient solution, also evaluating the electrical conductivity (EC) and $\mathrm{pH}$ of the solution. The structure had polypropylene hydroponic profiles, commercial diameter of $150 \mathrm{~mm}$, length of $2.5 \mathrm{~m}$,
\end{abstract}


with spacings of $0.50 \mathrm{~m}$ between plants by $0.90 \mathrm{~m}$ between profiles, totaling five plants per profile. The experimental design was completely randomized in a factorial scheme $(6 \times 2)$ referring to six levels of water salinity $\left(0.2,1.5,2.5,3.5,4.5\right.$ and $\left.5.5 \mathrm{dSm}^{-1}\right)$ and two application rates of the nutrient solution (1.5 and $2.5 \mathrm{~L} \mathrm{~min} \mathrm{-1),} \mathrm{with} \mathrm{four} \mathrm{replications} \mathrm{totaling}$ 48 experimental plots, produced by the application of $\mathrm{NaCl}$ in the supply water, these waters being used in the preparation of the solution nourishing and replacement of evapotranspirated volume. In both flow rates a tendency of increase of the electrical conductivity of the solution (CEsol) was verified in the treatments of higher salinity levels of the used water (4.5 and 5.5 $\mathrm{dSm}-1)$, however, in the flow of $2.5 \mathrm{~L} \mathrm{~min}-1$ and, for the same levels (4.5 and $5.5 \mathrm{dSm}-1)$, there were more significant increases. The $\mathrm{pH}$ of the nutrient solution remained within the normal range for both flow rates. The increase in the salinity provided increase in sodium and chloride contents, and reduction in potassium, phosphorus, calcium and magnesium contents in the diagnostic leaf. Sulfur content was not significantly influenced.

Keywords: Brassica olerácea L., Hidroponics, Salinity

\section{Introdução}

A escassez de água, tanto de forma quantitativa como qualitativa, tem sido uma constante preocupação ao longo da história da humanidade, porém, a partir da última década do século XX, este problema ficou ainda mais evidenciado devido ao crescimento populacional e a melhoria das condições de vida da população, o que demanda cada vez mais água (JUAN, 2000). Logo, diante deste cenário de baixa oferta de água potável, projetos de pesquisas e a geração de tecnologias que tornem possível a utilização de águas salobras para a produção de alimentos são de suma importância.

O cultivo hidropônico tem despontado como tecnologia alternativa para o uso condizente de águas salobras com seu maior aproveitamento na produção vegetal intensiva (SANTOS et al., 2010). É na hidroponia, onde se cultivam plantas sem a necessidade do solo, sendo a solução aquosa nutritiva a fonte dos nutrientes necessários ao desenvolvimento.

Segundo Furlani (1998), esta técnica vem se desenvolvendo rapidamente como meio de produção vegetal, pois é uma prática alternativa em cultivo protegido, com a possibilidade de elevadas produções em pequenas áreas, precocidade na colheita e cultivo durante qualquer época do ano (SOARES et al., 2007). Além disso, a maior disponibilidade de água e nutrientes nesse sistema de cultivo minimizam os efeitos severos da salinidade sobre as plantas (SANTOS et al., 2010).

Os cultivos hidropônicos podem constituir uma vantagem quando se utiliza água salobra, pois, neste sistema, inexiste o potencial mátrico devido ao estado de saturação aos 
quais as plantas estão submetidas, fato que possibilita o aumento da resposta das culturas à salinidade devendo isso representar uma maior absorção de água e nutrientes pelas plantas para uma mesma quantidade de sais (SOARES et al., 2007; SANTOS et al., 2010). Neste sistema, através do monitoramento da composição da solução nutritiva, é possível se ter um controle maior da eficiência dos nutrientes (HEINEN et al., 1991).

Contudo, sabe-se que o acúmulo e a extração de nutrientes pelas plantas dependem da condutividade elétrica da solução nutritiva existindo uma proporcionalidade em relação às concentrações dos íons responsáveis pelo potencial osmótico dessa solução afetando a absorção de água, de nutrientes, a produtividade entre outros distúrbios fisiológicos (SHANNON, 1997). Assim, condutividades elétricas elevadas podem mudar a taxa de absorção de nutrientes nas plantas em decorrência da diminuição da absorção de água sendo influenciada pelo potencial osmótico do meio nutritivo e, consequentemente a absorção de nutrientes (HUETT, 1994).

A salinização sobre as plantas pode causar efeitos pela dificuldade de absorção de água, toxidade de íons específicos e também pela própria interferência dos sais nos processos fisiológicos reduzindo o desenvolvimento das plantas. Dependendo do grau da salinidade pode ocorrer plasmólise, ou seja, a planta poderá perder água que se encontra em seu interior, em vez de absorver (DIAS \& BLANCO, 2010). O desequilíbrio nutricional em função da salinidade ocorre, sobretudo, da redução na absorção de nutrientes essenciais à planta devido à competição na absorção e transporte, às modificações estruturais nas membranas (ARAGÃO et al., 2010).

Com a utilização de águas salobras em hidroponia, espera-se a produção de culturas de interesse econômico como exemplo a couve-flor (Brassica oleracea L.) cultivar piracicaba precoce, desejando-se obter uma maior produção, com crescimento eficiente evitando o desperdício desnecessário de água.

A couve-flor é considerada boa fonte de potássio, é uma planta originária de clima frio, cujas cultivares ou híbridos necessitam de baixas temperaturas para a passagem da fase vegetativa para a reprodutiva. Desta forma a temperatura é o principal fator climático que afeta a produção de couve-flor. A faixa ótima de temperatura para couve-flor é de 14 a $20{ }^{\circ} \mathrm{C}$, e o cultivo em temperaturas acima de $25^{\circ} \mathrm{C}$ pode provocar a não-formação da inflorescência ou a perda de compacidade (MAY et al., 2007).

Em função da escassez de informações técnicas na literatura, se tornam necessários o 
conhecimento e a aplicação de técnicas de manejo do uso de água salobra na produção de couve-flor. Dentre essas técnicas está o cultivo hidropônico NFT, verificando a influência da vazão de aplicação da solução nutritiva na produção comercial da couve-flor.

Diante do exposto, objetivou-se com esta pesquisa avaliar os teores de macronutrientes, de sódio e de cloreto em plantas de couve-flor em função da salinidade da água de irrigação e de vazões de aplicação da solução nutritiva.

\section{Fundamentação Teórica}

No Semiárido a produção agrícola depende muito mais da irrigação do que em outras regiões,onde esta condição é justificada devido a escassez pluviométrica, porém a irrigação tem forte influência sobre os principais causadores de impactos ambientais negativos de origem antrópica no Semiárido, em evidência a salinização.

O problema da salinização pode ocorrer com o uso de água doce em condições de má drenagem do solo e de manejo incorreto da irrigação, e com o uso da água salobra há uma potencialização desse processo de salinização.

Com o intuito de encontrar meios de realizar um manejo adequado e aumentar a eficiência do uso da água, tem-se aplicado o uso da hidroponia que de acordo com Soares et al.(2007) a eficiência do uso dessa tecnologia é dada pela ausencia da matriz do solo, com isso, o potencial da água passa a depender decisivamente do potencial osmótico, elevando a tolerância das plantas à salinidade em relação ao cultivo convencional.

Algumas pesquisas tem sido conduzidas nos últimos anos buscando avaliar a viabilidade de aproveitamento de águas de qualidade inferior em cultivos hidropônicos a exemplo das pesquisas conduzidas por Amorim et al.(2005); Dias et al. (2010); Paulus et al. (2010); Santos et al.( 2010a, 2010b); Soares et al., (2010); Dentre outros.

Apesar do exposto, o aumento da salinidade da água mesmo em cultivo hidropônico pode ocasionar distúrbios nutricionais, principalmente às plantas sensíveis, tendo-se em vista que, a salinidade é um dos estresses abióticos que afeta de forma negativa vários fatores fisiológicos e bioquímicos nas plantas como, por exemplo, a acumulação excessiva de $\mathrm{Na}^{-} \mathrm{e}$ $\mathrm{Cl}^{-}$que causam desequilíbrio iônico o que reduz a absorção de outros nutrientes minerais como o $\mathrm{K}^{+}$e o $\mathrm{Ca}^{2+}$ (Abbasi et al., 2016). 
Faz-se necessário maiores investigações quanto a influência de outras variáveis a exemplo do exposto neste presente trabalho, e de avaliar mais plantas e cultivares a fim de suprir ou ao menos amenizar a necessidade da população.

\section{Metodologia}

A pesquisa foi desenvolvida no Departamento de Engenharia Agrícola da Universidade Federal Rural de Pernambuco, em ambiente protegido, tipo casa de vegetação e foi utilizada a couve-flor (cv. Piracicaba Precoce) cultivada em sistema hidropônico NFT sob níveis crescentes de salinidade da água utilizada no preparo da solução nutritiva $(0,2,1,5,2,5$, 3,5, 4,5 e 5,5 dS m m $^{-1}$ e duas vazões de aplicação desta solução nutritiva (1,5 e 2,5 L min $\left.{ }^{-1}\right)$, sendo essas águas obtidas pela adição de $\mathrm{NaCl}$ a água de abastecimento local $\left(0,2 \mathrm{dS} \mathrm{m}^{-1}\right)$. A reposição da lâmina evapotranspirada foi realizada com água salobra do respectivo tratamento. Os tratamentos foram distribuídos em delineamento experimental inteiramente casualizado em um esquema fatorial ( 6 x 2), com quatro repetições, totalizando 48 parcelas experimentais.

Foi utilizado o sistema Nutrient Film Technique - NFT adotando-se espaçamento de 0,50 m entre as plantas e 0,60 m entre perfis, a uma altura máxima em relação ao plano de referência inferior de $1,0 \mathrm{~m}$ com inclinação de 5\%. Utilizou-se água de abastecimento municipal do Recife-PE e para o estabelecimento dos níveis salinos (0,2 - água de abastecimento, 0,2; 1,5; 2,5; 3,5; 4,5 e 5,5 $\mathrm{dS} \mathrm{m}^{-1}$ ) adicionou-se $\mathrm{NaCl}$ (Richards, 1954).

Os fertilizantes utilizados no preparo da solução nutritiva conforme Furlani (1998) foram o nitrato de cálcio, nitrato de potássio, fosfato monoamônico (MAP), sulfato de magnésio, sulfato de cobre, sulfato de zinco, sulfato de manganês, ácido bórico, molibidato de sódio e Fe-EDTA-13\%. Após a homogeneização da solução, a condutividade elétrica da solução nutritiva inicial (CEsol), por tratamento, foi: 1,5, 2,5, 3,5, 4,5, 5,5 e 6,5 dS m . $^{-1}$.

A irrigação do experimento foi controlada por um temporizador mecânico (Timer) programado para realizar eventos de irrigação a cada 15 minutos.

As mudas de couve-flor cv. "Piracicaba Precoce" foram adquiridas de um viverista especializado local e a semeadura foi realizada em bandejas de 128 células preenchidas com o substrato pó de coco. As mudas foram mantidas em bandejas até 30 dias após a semeadura (DAS), nesse período foram irrigadas com solução nutritiva indicada por Furlani et al. (1999) com 50\% de diluição. Aos 30 (DAS) as plantas foram transplantadas para as unidades experimentais e iniciaram-se a aplicação dos tratamentos. 
Durante os experimentos foram realizados leituras de $\mathrm{pH}$ e condutividade elétrica da solução (CEsol) em dias alternados (um dia sim e outro não). Porém, visando simular condições reais de campo e supondo que o agricultor não disponibiliza de material para tal ajuste não foi realizado a correção do pH para faixa ideal entre 5,5 - 6,5. A substituição da solução nutritiva dos tratamentos foi realizada sempre que a condutividade elétrica da solução (CEsol) do tratamento controle (água com condutividade elétrica de $0,2 \mathrm{dS} \mathrm{m}^{-1}$ ) atingia valor inferior a $1,0 \mathrm{dS} \mathrm{m} \mathrm{m}^{-1}$.

A couve-flor foi colhida aos 49 DAT. Posteriormente, a parte aérea foi separada das raízes e levada à estufa de circulação de ar à temperatura de $65^{\circ} \mathrm{C}$ por 72 horas, onde atingiu a massa constante. Após esse procedimento, o material seco em estufa foi moído e armazenado em recipientes plásticos devidamente etiquetados.

A avaliação do estado nutricional das culturas foi realizada a partir da determinação das concentrações dos macronutrientes (fósforo, potássio, cálcio, magnésio e enxofre) na folha diagnóstico. Além desses, foram também quantificados os teores dos elementos cloreto e sódio. Todas essas determinações foram feitas pelos procedimentos metodológicos propostos por Bezerra Neto \& Barreto (2011), onde o sódio e potássio foi determinado pelo método de fotometria de chama, fósforo pelo método colorimétrico molibdo-vanadato, enxofre pelo método turbidimétrico do sulfato de bário, cloreto pelo método de Mohr, cálcio, magnésio pelo método utilizando espectrofotometria de absorção atômica.

Os dados foram submetidos à análise de variância pelo teste $\mathrm{F}$ e, quando constatados efeitos significativos à análise de regressão.

\section{Resultados e Discussão}

Na Figura 1 encontram-se os valores médios da condutividade elétrica da solução nutritiva obtidos durante todo o ciclo da couve-flor.

Os valores da condutividade elétrica da solução nutritiva $\left(\mathrm{CE}_{\mathrm{sol}}\right)$ foram influenciados pelas vazões utilizadas no exprimento sendo a vazão de $2,5 \mathrm{~L} \mathrm{~min}^{-1}$ a que proporcionou maiores aumentos percentuais em relação à $\left(\mathrm{CE}_{\text {sol }}\right)$ inicial. Verificou-se uma variação positiva de 31,8\% em relação à $\left(\mathrm{CE}_{\text {sol }}\right)$ inicial para o tratamento mais salino $\left(5,5 \mathrm{dS} \mathrm{m}^{-1}\right)$ com uma lâmina de aplicação de $1,5 \mathrm{~L} \mathrm{~min}^{-1}$ e uma variação negativa de $17,2 \%$ em relação à $\left(\mathrm{CE}_{\text {sol }}\right)$ inicial para o tratamento controle (Figura 1A). 
Verificou-se que a utilização da lâmina de $2,5 \mathrm{~L} / \mathrm{min}^{-1}$ proporcionou uma variação positiva de $48,4 \%$ em relação a $\left(\mathrm{CE}_{\text {sol }}\right)$ inicial para o tratamento mais salino e uma oscilação negativa de $21,1 \%$ para o tratamento controle $\left(0,2 \mathrm{dS} \mathrm{m}^{-1}\right)$ com a mesma lâmina (Figura 1B).

Figura 1. Valores médios de condutividade elétrica da solução (CEsol) nutritiva de couve-flor cultivadas com águas salobras em duas vazões de aplicação de solução nutritiva $\mathrm{L}_{1}=1,5 \mathrm{~L} \mathrm{~min}^{-1}$ e $\mathrm{L}_{2}=2,5 \mathrm{~L} \mathrm{~min}^{-1}$,

A.

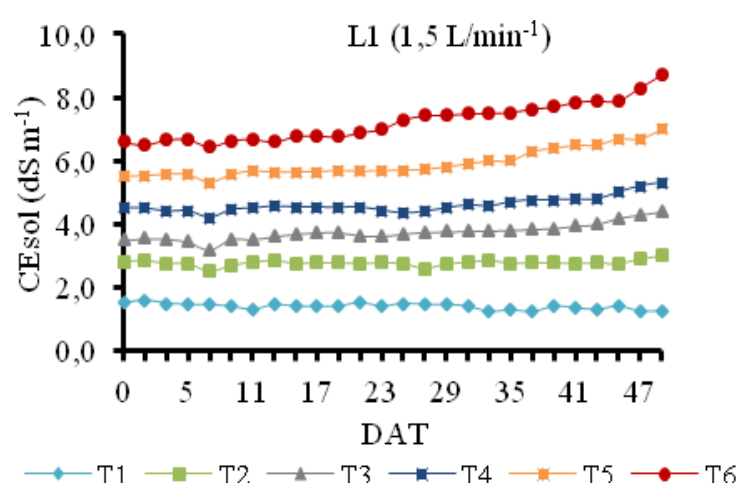
respectivamente.

B.

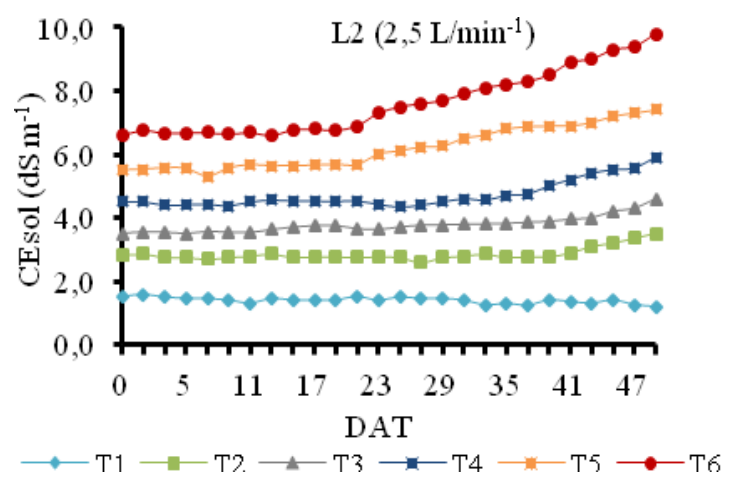

Fonte: Própria (2019)

A redução da $\left(\mathrm{CE}_{\mathrm{sol}}\right)$ para o tratamento controle ocorreu em função do consumo de nutrientes pelas plantas e pelo fato de não ter sido realizada troca da solução nutritiva durante o ciclo, com excessão aos 10 DAT.

Para os tratamentos 1,$5 ; 2,5 ; 3,5$ e $4,5\left(\mathrm{dS} \mathrm{m}^{-1}\right)$ ocorreu uma variação positiva de 6,3 , 25,7, 17,8 e 27,2\% em relação a CE inicial quando se utilizou a lâmina de 1,5 $\mathrm{L} \mathrm{min}^{-1}$. Quando foi utilizada a lâmina de $2,5 \mathrm{~L} \mathrm{~min}^{-1}$ para os mesmos tratamentos ocorreu uma variação positiva de 24,1,31,4, 33,3 e 34,5\% em relação a CE inicial.

$\mathrm{O}$ aumento da $\left(\mathrm{CE}_{\text {sol }}\right)$ para os demais tratamentos utilizando tanto a lâmina de 1,5 $\mathrm{L}$ $\min ^{-1}$ quanto a de $2,5 \mathrm{~L} \mathrm{~min}^{-1}$ ocorreu em função do acúmulo de sais provenientes do incremento dos níveis de salinidade da água utilizada para o preparo da solução nutritiva devido à reposição da lâmina evapotranspirada ter sido realizada com a água salobra do respectivo tratamento, Contudo, observa-se que a lâmina de $2,5 \mathrm{~L} \mathrm{~min}^{-1}$ forneceu um maior incremento de sais à solução nutritiva o que pode ser constatados pelos maiores aumentos percentuais da condutividade elétrica da solução nutritiva.

Estes valores corroboram com os resultados propostos por Soares et al. (2010), que avaliando a produção de hortaliças também observaram aumento da CE da solução nutritiva quando utilizaram águas salobras para reposição da evapotranspiração. 
De maneira geral, o pH da solução nutritiva oscilou dentro da faixa de 5,0 e 6,5 (Figura 2), ou seja, dentro de uma faixa na qual o $\mathrm{pH}$ não influencia negativamente as culturas, visto que de acordo com Furlani et al. (1999), variações de pH entre 4,5 e 7,5 não afetam o desenvolvimento das plantas em hidroponia, porém, para situações de acidez inferior a 4 pode ocorrer prejuízo na membrana das células e em situações de alcalinidade superior a 8 há deficiência de alguns nutrientes como o ferro e o fósforo.

Figura 2. Valores médios de pH (pHsol) da solução nutritiva em duas vazões de aplicação de solução nutritiva $\mathrm{L}_{1}$

A. $=1,5 \mathrm{~L} \mathrm{~min}^{-1}$ e $\mathrm{L}_{2}=2,5 \mathrm{~L} \mathrm{~min}{ }^{-1}$, respectivamente.

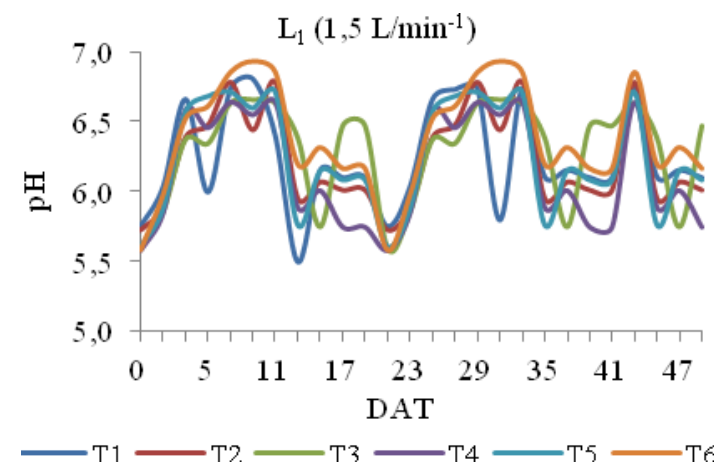

B.

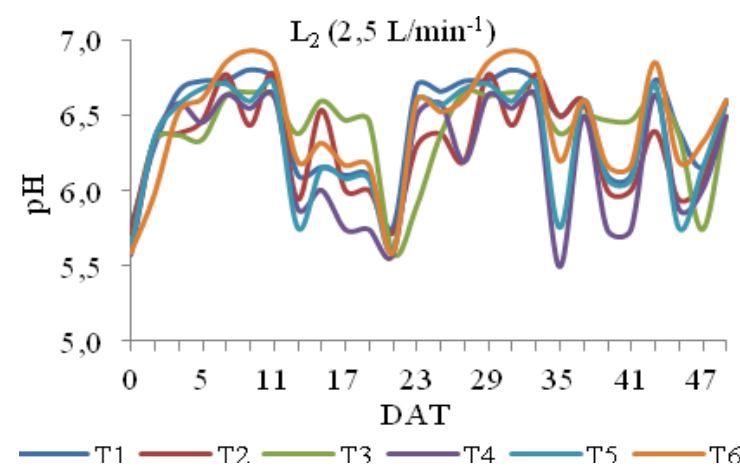

Fonte: Própria (2019).

De acordo com a análise de regressão aplicada aos dados (Figura 3) verifica-se que a salinidade da água utilizada para o preparo da solução nutritiva reduziu linearmente as variáveis analisadas com as respectivas vazões aplicadas $\left(1,5 \mathrm{~L} \mathrm{~min}{ }^{-1}\right.$ e $\left.2,5 \mathrm{~L} \mathrm{~min}{ }^{-1}\right)$. Verifica-se que na menor e maior vazão aplicada, houve uma redução percentual no consumo hídrico $(\mathrm{CH})$ na planta em detrimento do aumento unitário de salinidade da água utilizada no preparo da solução nutritiva em dS m${ }^{-1}$ na ordem de 7,64 \% (1,5 $\left.\mathrm{L} \mathrm{min}^{-1}\right)$ e $12,99 \%\left(2,5 \mathrm{~L} \mathrm{~min}^{-1}\right)$.

Os resultados obtidos nesta pesquisa para o consumo hídrico corroboram com aqueles encontrados por Lira et al. (2015) que, trabalhando com agrião e couve-chinesa em sistema hidropônico NFT também encontraram reduções do consumo hídrico com o aumento da salinidade da água utilizada no preparo da solução nutritiva.

Figura 3. Análise de regressão aplicada ao consumo $(\mathrm{CH})$ em função dos níveis de salinidade da água utilizada para o preparo da solução nutritiva $(\mathrm{CEw})$ e de vazões $\left(\mathrm{V} 1=1,5 \mathrm{~L} \mathrm{~min}^{-1}\right)$ e $\left(\mathrm{V} 2=2,5 \mathrm{~L} \mathrm{~min}^{-1}\right)$ de aplicação desta solução na cultura da couve-flor c.v. "Piracicaba Precoce". 


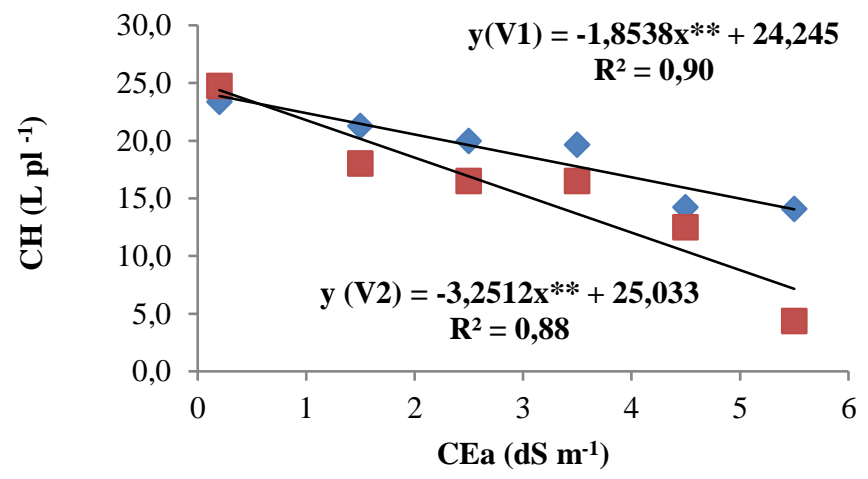

Fonte: Própria (2019).

O aumento da condutividade elétrica da solução nutritiva proporcionou efeitos significativos ao nível de $1 \%$ de probabilidade sobre os teores foliares de fósforo, cálcio, magnésio, cloreto, sódio e potássio (Tabela 1). Por outro lado, o enxofre não sofreu efeito significativo dos tratamentos utilizados.

Tabela 1. Resumo da análise de variância para os parâmetros de nutrição mineral na folha diagnóstico analisados em experimento com couve-flor cultivada em sistema hidropônico NFT.

\begin{tabular}{|c|c|c|c|c|c|c|c|}
\hline \multicolumn{8}{|c|}{ Teste F } \\
\hline F.V & $P$ & $S$ & $C a$ & $M g$ & $\mathrm{Cl}$ & $\mathrm{Na}$ & $K$ \\
\hline CEw & $510,71 * *$ & $0,33 \mathrm{~ns}$ & $240,56 * *$ & $177,22 * *$ & $236,73 * *$ & $4015 * *$ & $835 * *$ \\
\hline Vazão & $276,76 * *$ & $0,33 \mathrm{~ns}$ & $41,59 * *$ & $33,52 * *$ & $31,93 * *$ & $161 * *$ & $381 * *$ \\
\hline CEsol x & $16,69 * *$ & $0,38 \mathrm{~ns}$ & $7,01 * *$ & $5,61 * *$ & $3,58 * *$ & $321 * *$ & $23,53 * *$ \\
\hline \multicolumn{8}{|l|}{ Vazão } \\
\hline $\mathrm{CV}(\%)$ & 3,32 & 1,48 & 6,85 & 6,84 & 8,09 & 1,44 & 2,50 \\
\hline
\end{tabular}
Cloreto, $\mathrm{Na}$ - Sódio, $\mathrm{K}$ - Potássio, ns - não significativo.

Fonte: Própria (2019).

A análise de regressão aplicada aos dados revelou que os teores de fósforo, potássio, cálcio e magnésio na folha diagnóstico da cultura foram reduzidos em função do aumento da condutividade elétrica da solução nutritiva (Figuras 4A a 4D). Por outro lado, os teores de sódio e cloreto (Figuras 5A e 5B) foram incrementados em função do aumento dessa condutividade.

Figura 4. Teores de fósforo (P) (A), potássio (K) (B), cálcio (C) e Mg (D) na folha diagnóstico da cultura em função dos níveis de salinidade da água utilizada para o preparo da solução nutritiva (CEa) e de vazões (V1 = 1,5 $\left.\mathrm{L} \mathrm{min}^{-1}\right)$ e $\left(\mathrm{V} 2=2,5 \mathrm{~L} \mathrm{~min}^{-1}\right)$ de aplicação desta solução. 


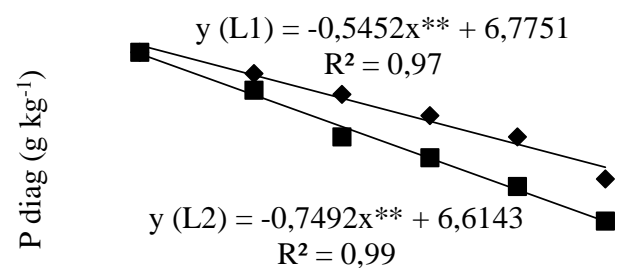

$\mathrm{CE}\left(\mathrm{dS} \mathrm{m} \mathrm{m}^{-1}\right)$

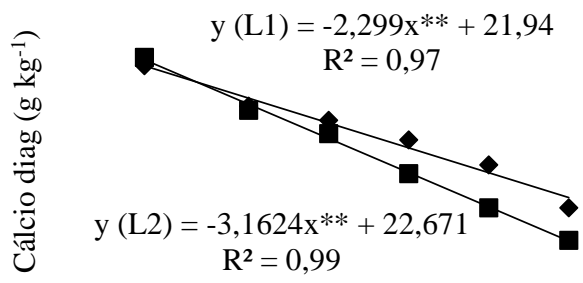

$\mathrm{CEa}\left(\mathrm{dS} \mathrm{m} \mathrm{m}^{-1}\right)$
A

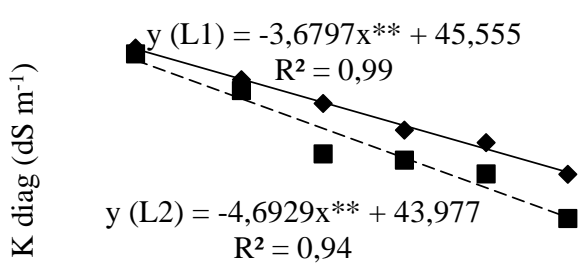

$\mathrm{CEa}\left(\mathrm{dS} \mathrm{m}{ }^{-1}\right)$

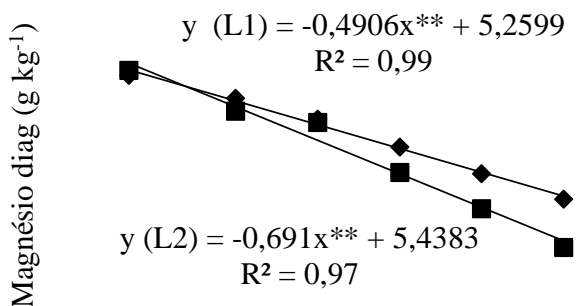

$\mathrm{CEa}\left(\mathrm{dS} \mathrm{m} \mathrm{m}^{-1}\right)$
C

Fonte: Própria (2019).

Figura 5. Teores de sódio (Na) (A) e cloreto $(\mathrm{Cl})(\mathrm{B})$ na folha diagnóstico da cultura em função dos níveis de salinidade da água utilizada para o preparo da solução nutritiva $(\mathrm{CEa})$ e de vazões $\left(\mathrm{V} 1=1,5 \mathrm{~L} \mathrm{~min}^{-1}\right)$ e $(\mathrm{V} 2=$ 2,5 $\mathrm{L} \mathrm{min}^{-1}$ ) de aplicação desta solução.

A

B

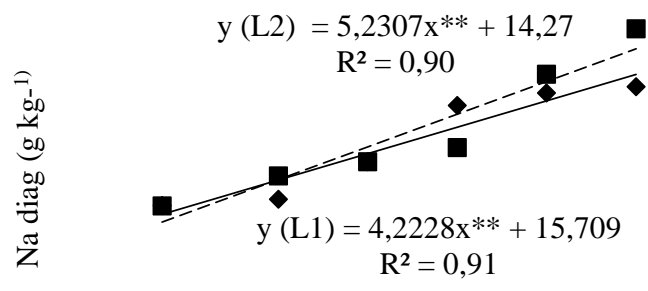

$\mathrm{CEa}\left(\mathrm{dS} \mathrm{m} \mathrm{m}^{-1}\right)$

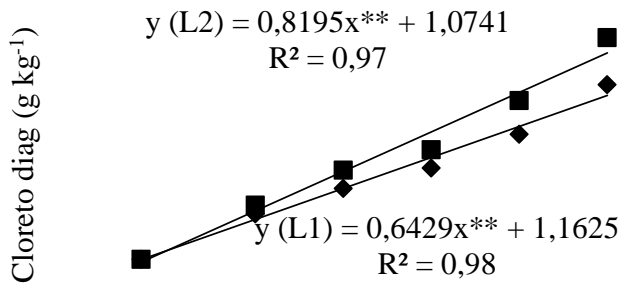

$\mathrm{CEa}\left(\mathrm{dS} \mathrm{m} \mathrm{m}^{-1}\right)$

Fonte: Própria (2019).

Verifica-se que na vazão de $1,5 \mathrm{~L} \mathrm{~min}^{-1}$ houve aumento linear por incremento unitário da CEa de 26,8\% para o teor de sódio na folha diagnóstico da cultura (Figura 5A) e redução linear por incremento unitário da CEa de 8,0\% para o teor de potássio (Figura 4B). Por outro lado, a utilização da vazão de $2,5 \mathrm{~L} \mathrm{~min}^{-1}$ proporcionou aumento linear por incremento unitário da CEa de 36,6\% para o sódio e redução por acréscimo unitário da CEa de $10,6 \%$ para o teor de potássio.

Ainda de acordo com a Figura 5A, estimam-se valores da ordem de $38,9 \mathrm{~g} \mathrm{~kg}^{-1}$ de matéria seca para o sódio na folha diagnóstico na maior salinidade da água $\left(5,5 \mathrm{dS} \mathrm{m} \mathrm{m}^{-1}\right)$ 
utilizando a vazão de $1,5 \mathrm{~L} \mathrm{~min}^{-1}$, resultado este $10,53 \%$ menor que observado quando se utilizou a vazão de $2,5 \mathrm{~L} \mathrm{~min}^{-1}$ que apresentou valor estimado da ordem de $43 \mathrm{~g} \mathrm{~kg}^{-1}$ de matéria seca. Para o potássio (Figura 4B) na mesma salinidade da água utilizando a vazão de 1,5 $\mathrm{L} \mathrm{min}{ }^{-1}$ estimam-se valores da ordem de $25,3 \mathrm{~g} \mathrm{~kg}^{-1}$ de matéria seca, resultado esse $28,2 \%$ maior que observado quando se utilizou a vazão de $2,5 \mathrm{~L} \mathrm{~min}^{-1}$ que apresentou valor estimado da ordem de $18,1 \mathrm{~g} \mathrm{~kg}^{-1}$ de matéria seca.

$\mathrm{O}$ teor de $\mathrm{K}$ na folha diagnóstico encontrado nesta pesquisa utilizando a maior salinidade da água (5,5 dS m$\left.{ }^{-1}\right)$ e a vazão de aplicação de solução nutritiva de $2,5 \mathrm{~L} \mathrm{~min}^{-1}$ foi de $25,3 \mathrm{~g} \mathrm{~kg}^{-1}$. Esse valor está abaixo da faixa de teores considerados adequados para a couve-flor que é 30-50 $\mathrm{g} \mathrm{kg}^{-1}$ de matéria seca segundo Trani \& Raij (1997).

As constatações de aumentos consideráveis dos teores de sódio na folha diagnóstico das plantas em função do incremento dos níveis de salinidade e, a redução dos teores de potássio, em ambas as vazões avaliadas, deve-se à competição entre estes íons pelo mesmo sítio de absorção e transporte na membrana plasmática. Desta forma, em função deste antagonismo iônico entre esses elementos, as concentrações de $\mathrm{K}$ no tecido foliar das plantas foram reduzidas pelas concentrações crescentes de Na (SOARES et al., 2016).

A presença do sódio pode contribuir para o crescimento vegetal, pois, o sódio ( $\mathrm{Na}$ ) é considerado um elemento benéfico para algumas plantas, todavia, a planta completa o seu ciclo de vida sem esse elemento (MALAVOLTA, 2006). Já o potássio participa do processo de abertura e fechamento dos estômatos regulando a transpiração e a entrada de $\mathrm{CO}_{2}$, influencia a fotossíntese promovendo a síntese de enzimas e atua na translocação de assimilados (BLOOM \& EPSTEIN, 2006).

Os resultados obtidos nesta pesquisa para os teores de sódio nas duas vazões corroboram com aqueles encontrados por Giuffrida et al. (2016) que, avaliando o crescimento da couve-flor encontraram valores da ordem de $23,8 \mathrm{~g} \mathrm{~kg}^{-1}$ de matéria seca para o sódio na folha diagnóstico com salinidade de $4 \mathrm{dS} \mathrm{m}^{-1}$ aos 84 DAT. Possivelmente os resultados de sódio encontrados nesta pesquisa foram superiores aos descritos acima quando se utilizou a vazão de $2,5 \mathrm{~L} \mathrm{~min}^{-1}$ que foram da ordem de $34,5 \mathrm{~g} \mathrm{~kg}^{-1}$ de matéria seca em virtude dos níveis de salinidades utilizados nesta pesquisa e o uso do $\mathrm{NaCl}$ como única fonte usada para salinização das águas e, principalmente, a interação com a vazão de aplicação de solução nutritiva utilizada, além do fato de que a reposição da lâmina evapotranspirada foi realizada com água salobra do respectivo tratamento. 
Com relação aos teores de fósforo e de cálcio, estes foram influenciadas pelo incremento unitário da condutividade elétrica da solução nutritiva e as vazões de aplicação (Figura 4A e 4C). Verifica-se na vazão de $1,5 \mathrm{~L} \mathrm{~min}^{-1}$ redução linear por incremento unitário da CEa de 8\% para o fósforo (Figura 4A) e redução linear por incremento unitário da CEa de 10,4\% para o cálcio (Figura 4C). A vazão de $2,5 \mathrm{~L} \mathrm{~min}^{-1}$ proporcionou redução linear por incremento unitário da CEa de $11,3 \%$ para o fósforo e redução por acréscimo unitário da CEa de 13,9\% para os teores de cálcio na folha diagnóstico. De acordo com o modelo linear estimam-se valores da ordem de $3,7 \mathrm{~g} \mathrm{~kg}^{-1}$ de matéria seca para o fósforo na folha diagnóstico na maior salinidade da água $\left(5,5 \mathrm{dS} \mathrm{m}^{-1}\right)$ utilizando a vazão de $1,5 \mathrm{~L} \mathrm{~min}$ 1, e na vazão de $2,5 \mathrm{~L} \mathrm{~min}^{-1}$ o valor estimado é da ordem de $2,49 \mathrm{~g} \mathrm{~kg}^{-1}$ de matéria seca. Para o cálcio na mesma salinidade da água utilizando a vazão de $1,5 \mathrm{~L} \mathrm{~min}^{-1}$ estima-se valores da ordem de 9,29 $\mathrm{g} \mathrm{kg}^{-1}$ de matéria seca, e na vazão de $2,5 \mathrm{~L} \mathrm{~min}^{-1} \mathrm{o}$ valor estimado é da ordem de $5,27 \mathrm{~g} \mathrm{~kg}^{-1}$ de matéria seca.

Para os teores de magnésio e cloreto na folha diagnóstico (Figura 4D e 5B), verificase na vazão de $1,5 \mathrm{~L} \mathrm{~min}^{-1}$ redução linear por incremento unitário da CEa de 9,3\% para o magnésio (Figura 4D) e aumento linear por incremento unitário da CEa de 55,3\% para cloreto (Figura 5B). Por outro lado, a utilização da vazão de $2,5 \mathrm{~L} \mathrm{~min}^{-1}$ proporcionou redução linear por incremento unitário da CEa de 12,7\% para o magnésio e aumento por acréscimo unitário da CEa de 76,2\% para os teores de cloreto na folha diagnóstico. De acordo com o modelo linear estimam-se valores da ordem de $2,5 \mathrm{~g} \mathrm{~kg}^{-1}$ de matéria seca para o magnésio na folha diagnóstico na maior salinidade da água $\left(5,5 \mathrm{dS} \mathrm{m}^{-1}\right)$ utilizando a vazão de 1,5 $\mathrm{L} \mathrm{min}^{-1}$, e para vazão de 2,5 $\mathrm{L} \mathrm{min}^{-1} \mathrm{o}$ valor estimado foi da ordem de $1,6 \mathrm{~g} \mathrm{~kg}$ ${ }^{1}$ de matéria seca. Para o cloreto na mesma salinidade da água utilizando a vazão de 1,5 L $\min ^{-1}$ estima-se valores da ordem de $4,6 \mathrm{~g} \mathrm{~kg}^{-1}$ de matéria seca e para vazão de $2,5 \mathrm{~L} \mathrm{~min}^{-1} \mathrm{o}$ valor estimado foi da ordem de $5,5 \mathrm{~g} \mathrm{~kg}^{-1}$ de matéria seca.

Cramer et al. (1994) estudando diferentes níveis de salinidade na cultura do milho também verificaram reduções na concentração de cálcio no tecido foliar em função do aumento da salinidade da solução nutritiva proporcionado pelo sódio.

De acordo com Munns \& Teste (2008) e Rigon et al. (2012), de modo geral, a salinidade tem reflexo negativo no desenvolvimento das plantas, em especial na redução do sistema radicular e da área foliar. O que pode ser explicado devido a altos níveis de $\mathrm{Na}$ e $\mathrm{Cl}$, que podem provocar a inibição da absorção dos íons $\mathrm{K}$, Ca pelas raízes, provocando 
sintomas de deficiências, como redução no crescimento.

Com relação a concentração de $\mathrm{Cl}$ nas folhas, apesar da maioria das plantas geralmente absorverem $\mathrm{Cl}$ em níveis acima do necessário ao seu metabolismo (TAIZ \& ZEIGER, 2003), os teores médios de $\mathrm{Cl}$ encontrados nas folhas da couve-flor provocaram efeitos antagônicos sobre o fósforo, porém no caso do enxofre o cloreto não interferiu na sua absorção tendo em vista a não constatação de diferença significativa entre os tratamentos empregados.

\section{Conclusões}

Em ambas as vazões, houve aumento CEsol nos dois maiores níveis de salinidade da água utilizada (4,5 e 5,5 $\left.\mathrm{dS} \mathrm{m}^{-1}\right)$, porém, na vazão de 2,5 $\mathrm{L} \mathrm{min}^{-1}$ e, para os mesmos níveis, os acréscimos foram mais acentuados.

$\mathrm{O}$ pH da solução nutritiva permaneceu dentro da faixa de normalidade para ambas as vazões.

O aumento da salinidade da água reduziu o consumo hídrico da cultura, independentemente das vazões de aplicação da solução nutritiva avaliadas, porém, as reduções foram mais acentuadas na vazão de $2,5 \mathrm{~L} \mathrm{~m}^{-1}$.

O aumento da salinidade da água utilizada para o preparo da solução nutritiva reduziu os teores de $\mathrm{P}, \mathrm{K}, \mathrm{Ca}$ e $\mathrm{Mg}$ e aumentou os teores de $\mathrm{Na}$ e $\mathrm{Cl}$ na folha diagnóstico da cultura.

A vazão de $1,5 \mathrm{~L} \mathrm{~min}^{-1}$ foi a que proporcionou os menores valores de $\mathrm{Na}$ e $\mathrm{Cl}$ e maiores valores de $\mathrm{P}, \mathrm{K}, \mathrm{Ca}$ e $\mathrm{Mg}$ na folha diagnóstico da cultura.

\section{Referências}

ABBASI, H.; JAMIL, M.; HAQ, A.; ALI, S.; AHMAD, R.; MALIK, Z.; PARVEEN. Salt stress manifestation on plants, mechanism of salt tolerance and potassium role in alleviating it: a review. Zemdirbyste-Agriculture, v. 103, n. 2, p. 229-238, 2016.

AMORIM, D. M. B.; NOTARO, I. A.; FURTADO, D. A.; GHEYI, H. R.; BARACUHY, J. G. V. Avaliação de diferentes níveis de salinidade da água utilizada na produção de forragem hidropônica de milho. Revista Brasileira de Engenharia Agrícola e Ambiental, v.9, p.339$342,2005$. 
ARAGÃO, R. M.; SILVEIRA, J. A. G.; SILVA, E. N.; LOBO, A. K. M.; DUTRA, A. T. B. Absorção, fluxo no xilema e assimilação do nitrato em feijão-caupi submetido à salinidade. Revista Ciência Agronômica, v.14, p.100-106, 2010.

BEZERRA NETO, E.; BARRETO, L. P. Análises químicas e bioquímicas em plantas. Recife: UFRPE, Editora Universitária, 2011. 267p.

BLOOM, A. J; EPSTEIN, E. Nutrição Mineral de Plantas - Princípios e perspectivas. 2. ed. 2006.

CRAMER, G. R, ALBERICO, G. J.; SCHMIDT, C. Salt tolerance is not associated with the sodium accumulation of two maize hybrids. Australian Journal of Plant Physiology, v. 21, p. 675-692, 1994.

DIAS, N. S.; BLANCO, F. F. Efeitos dos sais no solo e na planta. Instituto nacional de Ciência e Tecnologia em Salinidade, 2010.

DIAS, N. S.; LIRA, R. B.; BRITO, R. F.; SOUZA NETO, O. N.; FERREIRA NETO, M.; OLIVEIRA, A. M. Produção de melão rendilhado em sistema hidropônico com rejeito da dessalinização de água em solução nutritiva. Revista Brasileira de Engenharia Agrícola e Ambiental, v.14, p. 755-761, 2010.

FURLANI, P. R. Hydroponic vegetable production in Brazil. Acta Horticulturae, v. 2, p. 777 $778,1999$.

FURLANI, P. R. Instrução para o cultivo de hortaliça de folha técnica pela técnica de hidroponia NFT. Campinas: Instituto Agronômico. 1998. 30p. (Documentos IAC, 168).

FURLANI, P. R., BOLONHESI, L. C. P.; FANQUIN, V. Cultivo hidropônico de plantas. Campinas. Instituto Agronômico. 1999. (Boletim técnico, 180).

GIUFFRIDA, FRANCESCO.; CASSANITI, C.; MALVUCCIO, A.; LEONARDI, C. Effects of salt stress imposed during two growth phases on cauliflower production and quality. Journal of the Science of Food and Agriculture, v. 97, p. 1552-1560, 2016.

HEINEN, M.; JAGER, A.; NIERS, H. Uptake of nutrients by lettuce on NFT with controlled composition of the nutrient solution. Netherlands Journal of Agricultural Science, v. 39, p. 197-212, 1991.

HUETT, D. O. Growth, nutrient uptake and tipburn severity of hidroponic lettuce in response to electrical conductivity and $\mathrm{K}$ : Ca ratio in solution. Australian Journal of Agricultural Research, v. 45, p. 251-267, 1994.

JUAN, J. A. M. S. Desalación de aguas salobres y de mar: osmose inversa. Madrid: Mundi-Prensa, 2000. 395 p. 
LIRA, R. M.; SILVA, E. F. F.; SILVA, G. F.; SANTOS, A. N. Production, water consumption and nutriente contente of Chinese cabbage grown hydroponiacally in brackish water. Revista ciência agronômica, v. 46, p. 497-505, 2015.

MALAVOLTA, E. Manual de nutrição mineral de plantas. São Paulo: Agronômica Ceres, 2006. 638 p.

MAY, A; TIVELLI, S. W; VARGAS, P. F; SAMRA, A. G; SACCONI, L. V; PINHEIRO, M. Q. A cultura da couve-flor. (Série Tecnologia APTA, Boletim Técnico IAC, 2007). 36 p. Campinas: Instituto Agronômico, 2007.

MUNNS, R.; TESTER, M. Mechanisms of salinity tolerance. Annual Review of Plant Biology, v. 59, p. 651-681, 2008.

PAULUS, D.; DOURADO NETO, D.; FRIZZONE, J. A.; SOARES, T. M. Produção e indicadores fisiológicos de alface sob hidroponia com água salina. Horticultura Brasileira, v.28, p.29-35, 2010.

RIGON, J. P. G.; CAPUANI, S.; BELTRÃO, N. M.; BRITO NETO, J. F.; SOFIATTI, V.; FRANÇA, V. F. Non-destructive determination of photosynthetic pigments in the leaves of castor oil plants. Acta Scientiarum. Agronomy, v. 34, p. 325-329, 2012.

SANTOS, A. N.; SOARES, T. M.; SILVA, E. F. DE F. E; SILVA, D. J. R.; MONTENEGRO, A. A. A. Cultivo hidropônico de alface com água salobra subterrânea e rejeito da dessalinização em Ibimirim, PE. Revista Brasileira de Engenharia Agrícola e Ambiental, v.14, p.961-969, 2010a.

SANTOS, A. N; SOARES, T. M; SILVA, E. F. F; MONTENEGRO, A. A. A. Cultivo hidropônico de alface com agua salobra subterrânea e rejeito da dessalinização em Ibimirim, PE. Revista Brasileira de Engenharia Agrícola e Ambiental, v. 14, p. 961- 969, 2010.

SANTOS, R. S.; DIAS, N. S.; SOUSA NETO, O. N.; GURGEL, M. T. Uso do rejeito da dessalinização de água salobra no cultivo da alface (Lactuca sativa L.) em sistema hidropônico NFT. Ciência e Agrotecnologia, v.34, p.983-989, 2010b.

SHANNON, M. C. Adaptation of plants to salinity. Advances in Agronomy, Newark, v. 60, p. $75-120,1997$.

SOARES, H. R.; SILVA, E. F. F.; SILVA, G. F.; LIRA, R. M.; BEZERRA, R. R. Mineral nutrition of crisphead lettuce grown in a hydroponic system with brackish water. Revista Caatinga, v. 29, p. 656-664, 2016.

SOARES, T. M. Utilização de águas salobras no cultivo da alface em sistema hidropônico NFT como alternativa agrícola condizente ao semi-árido brasileiro. 2007. 267 p. Tese (Doutorado). Escola Superior de Agricultura "Luiz de Queiroz", Universidade de São Paulo, Piracicaba, 2007. 
SOARES, T. M.; DUARTE, S. N.; SILVA, E. F. F.; MÉlO, R. F.; JORGE, C. A.; OLIVEIRA, A. S. Experimental structure for evaluation of brackish water use in lettuce hydroponic production. Irriga, v.14, p.102-114, 2009.

SOARES, T. M.; SILVA, E. F. F.; DUARTE, S. N.; MÉLO, R. F.; JORGE, C. A.; BONFIMSILVA, E. M.. Produção de alface utilizando águas salinas em sistema hidropônico. Irriga, v. 12, p. 235-248, 2007.

TAIZ, L.; ZEIGER, E. Fisiologia Vegetal. 3. ed. Porto Alegre: Artmed Editora S.A., 2003. TRANI, P. E.; RAIJ, B. van. Hortaliças in: RAIJ, B. van, CANTARELLA, H.; QUAGGIO, J. A.; FURLANI, A. M. C. Recomendações de adubação e calagem para o Estado de São Paulo. Campinas: Fundação IAC, 1997. p. 157-185 (Boletim Técnico 100). 